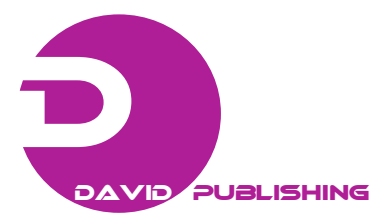

\title{
Assessment of E. coli and Salmonella in Chinese Cabbage Supply Chain in Cambodia
}

\author{
Vinit Set* ${ }^{1}$, Yasuhiro Inatsu ${ }^{2}$, Borarin Buntong ${ }^{1}$, Sopheap $\mathrm{Ek}^{1}$, Thong Kong ${ }^{1}$ and Vouchsim Kong ${ }^{1}$ \\ 1. Royal University of Agriculture, P.O. Box 2696, Phnom Penh, Cambodia \\ 2. Food Hygiene Laboratory, National Food Research Institute, NARO, Tsukuba, Japan \\ *Corresponding author's e-mail: setvinit@yahoo.com
}

\begin{abstract}
Contaminations of E.coli and Salmonella on vegetables are the major cause of bacterial foodborne diarrhea in humans worldwide. Fresh vegetables normally carry natural non-pathogenic epiphytic microorganisms, but during growth, harvest, transportation and further handling the produce can be contaminated with foodborne pathogens from animals and human sources. In most cases, these products are consumed raw or lightly cooked, so that their microbial content may represent a risk factor for the consumers' health, which is a food safety concern. This study aimed to identify and compare the number of E.coli and Salmonella in Chinese Cabbage Supply Chain. Three replicates of samples were collected from farms, wholesalers, and retailers following by three supply chain actors/processes. By this three supply chains actor, 9 samples at farms, 9 samples at wholesalers, and 9 samples at retailers had collected for experiment. E.coli was confirmed by inoculating into sterile EC medium then streaking on Eosin Methylene Blue EMB agar and identified by Triple Sugar Iron (TSI) and Lysine Indole Mobility (LIM) agars. Furthermore, Salmonella was confirmed by inoculating in to sterile Brilliant Green Lactose Bile (BGLB) medium tube then streaking on selective Deoxycholate Hydrogen sulfide Lactose (DHL) agar and identified by TSI and LIM agars. The results showed that the contamination of E.coli was found in average of $11.9 \times 10^{2} \mathrm{CFU} / \mathrm{g}$ (or $3.1 \mathrm{log} \mathrm{CFU} / \mathrm{g}$ ) in farms, $27.33 \times 10^{2} \mathrm{CFU} / \mathrm{g}$ (or $3.4 \mathrm{log} \mathrm{CFU} / \mathrm{g}$ ) in the wholesaler, and $9.64 \times 10^{2} \mathrm{CFU} / \mathrm{g}$ (or $2.3 \mathrm{log} \mathrm{CFU} / \mathrm{g}$ ) in retailer. For the number of Salmonella, itwas found in average of $11.73 \times 10^{2}$ CFU/g (or $3.1 \mathrm{log}$ CFU/g) in farm, $15.33 \times 10^{2} \mathrm{CFU} / \mathrm{g}$ (or $3.2 \mathrm{log} \mathrm{CFU} / \mathrm{g}$ ) in wholesaler, and also $10.27 \times 10^{2}(\log =3.0119) \mathrm{CFU} / \mathrm{g}$ in retailer. E.coli and Salmonella were found in highly number in the wholesaler comparing to the other two actors in supply chain which may be cause of poor hygiene conditions in their practice. Therefore, improving practice in this chain should be strongly taken into consideration before the produces continue supplying to the retailer as well as to the consumer.
\end{abstract}

Key words: E. coli, Salmonella, Chinese cabbage, cambodia, supply chain. 